\title{
Prospective study of physical activity and the risk of symptomatic diverticular disease in men
}

W H Aldoori, E L Giovannucci, E B Rimm, A Ascherio, M J Stampfer, G A Colditz, A L Wing, D V Trichopoulos, W C Willett

\begin{abstract}
The relationship between physical activity and risk of symptomatic diverticular disease has not been investigated directly. This association was examined in a prospective cohort of 47678 American men, 40 to 75 years of age, and free of diagnosed diverticular disease, colon or rectal polyp, ulcerative colitis, and cancer before 1988. During four years of follow up, 382 newly diagnosed cases of symptomatic diverticular disease were documented. After adjustment for age, energy adjusted dietary fibre, and energy adjusted total fat, overall physical activity was inversely associated with the risk of symptomatic diverticular disease (for highest versus lowest extremes, relative risk $(R R)=0.63(95 \%$ confidence interval (CI) $0.45,0.88$ ). Most of the inverse association was attributable to vigorous activity, for extreme categories $\mathbf{R R}=\mathbf{0 . 6 0}$ $(95 \%$ CI $0.41,0.87)$. For activity that was not vigorous the $R R$ was $0.93(95 \%$ CI 0.67 , 1.69). Several specific activities were inversely associated with the risk of diverticular disease, but jogging and running combined was the only individual activity that was statistically significant ( $p$ for trend $=0 \cdot 03$ ). For men in the lowest quintile for dietary fibre intake and total physical activity (compared with those in the opposite extreme), the $R R$ was 2.56 (95\% CI 1.36, 4.82). Physical activity, along with a high fibre diet, may be an important factor in the prevention of symptomatic diverticular disease.

(Gut 1995; 36: 276-282)
\end{abstract}

Keywords: diverticular disease, diverticula, colon, physical activity, exercise, cohort.

Diverticular disease is one of the most common disorders of the colon among the elderly in western societies, ${ }^{1}$ where it is estimated to occur in one third of people older than 45 years of age and in two thirds of those aged more than 85 years. $^{2}$ In most cases the condition is asymptomatic, ${ }^{3}$ and only between 10 and $25 \%$ of those affected develop symptoms. ${ }^{2}$ Symptomatic diverticular disease results in 200000 admissions to hospital in the USA annually. ${ }^{4}$

Earlier this century diverticular disease was widely believed to be rare, and was regarded as a pathological curiosity. This prompted Burkitt and Painter to call it 'a 20th century problem' or 'a disease of Western civilisation', 56 in contrast to its rarity in many developing countries. ${ }^{7}$ This sharp contrast was largely attributed to dietary differences, mainly in the decline of dietary fibre intake from cereal grains. ${ }^{5}$ The dietary fibre hypothesis is supported by human ${ }^{8-13}$ and animal studies. ${ }^{14-16}$ Previous case-control studies have found that patients consumed less fibre than controls, and we observed similar findings in the prospective health professionals follow-up study (unpublished). However, other potential risk factors, such as physical activity, body composition, smoking, alcohol, coffee drinking, total energy intake, and other dietary components, might also explain the difference in rates between developed and developing countries. Several studies, ${ }^{17-20}$ reported an effect of physical activity on colonic functions, particularly a reduction in transit time, suggesting that activity might also reduce the risk of diverticular disease. This hypothesis, however, has not been prospectively investigated.

\section{Methods}

\section{STUDY POPULATION}

The health professionals follow-up study is a prospective study of heart disease and cancer among 51529 US male health professionals, aged 40-75 years in 1986. The study began in 1986 when cohort members completed a detailed food frequency questionnaire and provided information about medical history, age, weight, height, smoking, alcohol consumption, physical activity, and history of professionally diagnosed medical conditions. Every two years $(1988,1990,1992)$ follow up questionnaires have been sent to update information on potential risk factors and to identify newly diagnosed cases of various diseases. The 1990 and 1992 follow up questionnaires contained specific questions regarding diverticular disease.

We excluded a priori from this analysis men whose average daily energy intake, calculated from the food frequency questionnaire, was outside the range of 3.35 to $17 \cdot 6 \mathrm{MJ}$ ( 800 to $4200 \mathrm{kcal}$ ), and those who left blank 70 or more food items on the dietary questionnaire. We also excluded men who reported previous cancer (other than non-melanoma skin cancer), colon or rectal polyp, ulcerative colitis, and diverticular disease before 1988. After exclusions, the eligible baseline population consisted of 47678 men. 
ASSESSMENT OF PHYSICAL ACTIVITY

The 1986 baseline questionnaire included a self reported assessment of mainly recreational physical activity. The reliability and validity of using questionnaires to assess physical activity have been investigated, ${ }^{21-23}$ and a similar questionnaire to the one used in this cohort was validated in a cohort of US women. ${ }^{24}$ Eight moderate or vigorous activities were listed on the questionnaire and participants were asked to report the average time per week spent at each activity: there were 10 possible responses ranging from $0 \mathrm{~min}$ to $\geqslant 11 \mathrm{~h} / \mathrm{wk}$. We also inquired about the number of flights of stairs climbed daily, usual walking pace and, in the 1988 follow up questionnaire, about the time spent watching video and television: there were six possible responses ranging from $0-1 \mathrm{~h} / \mathrm{wk}$ to $\geqslant 41 \mathrm{~h} / \mathrm{wk}$. Subjects who completed none of the activity responses were excluded from the analysis. The contribution of each activity was based on its energy expenditure requirements in METs, ${ }^{25}$ multiplied by the duration of the activity. One MET is defined as the energy expended sitting quietly which is equivalent to $3.5 \mathrm{ml}$ of oxygen uptake per $\mathrm{kg}$ of body weight per minute for a $70 \mathrm{~kg}$ adult. Body weight was not included in the derivation of energy expenditure of physical activity ( $\mathrm{kcal} / \mathrm{wk})$, because this could induce confounding by body weight, which is itself usually associated with physical activity. If more than one published intensity level was available for a given activity, the moderate or general MET value was chosen. An average MET value was assigned for the categories that listed more than one activity (for example, rowing and callisthenics, or squash and racquetball). The contributions from each activity were summed to give a physical activity index in total METs expressed as $\mathrm{h} / \mathrm{wk}$.

We further classified sports and other recreational activities into vigorous and nonvigorous activities according to their intensity. Sports with a score of MET value <6 METs were considered non-vigorous, and those scoring $\geqslant 6 \mathrm{MET}$ s as vigorous. Accordingly, the non-vigorous activities included walking or hiking outdoors, and stair climbing. The vigorous activities included jogging (slower than $10 \mathrm{~min} / \mathrm{mile}$ ), running (10 $\mathrm{min} / \mathrm{mile}$ or faster), bicycling (including stationary machines). lap swimming, calisthenics or rowing, squash or racquetball, and tennis.

\section{OTHER VARIABLES}

To assess dietary intake, we used a semiquantitative food frequency questionnaire that was validated in this cohort. ${ }^{26}$ The questionnaire included 131 food items plus vitamins and mineral supplements that collectively account for over $90 \%$ of the major nutrients consumed by participants. The values for dietary fibre were based on the work of Southgate et al. ${ }^{27} 28$ The body mass index (BMI) was computed in metric units (by dividing the weight in $\mathrm{kg}$ by the height in $\mathrm{m}^{2}$ ) from the participants' reports in the 1986 baseline questionnaire of their own height in inches and weight in pounds. Total energy intake was computed from the participants' reported intake of food items and alcohol on the food frequency questionnaire. ${ }^{26}$

\section{IDENTIFICATION OF DIVERTICULAR DISEASE}

CASES

Follow up questionnaires were sent to all study participants in 1988, 1990, and 1992. In the 1990 and 1992 questionnaires we asked whether diverticular disease had been diagnosed during the previous two years (diverticular disease was not a specified end point in the 1988 follow up questionnaire). After up to six mailings for each follow up period, the response rates were $96 \%$ in 1990 and $94 \%$ in 1992 (as of the time of this analysis). When diverticular disease was reported on the follow up questionnaire, we mailed the cohort member a supplementary questionnaire to confirm the reporting, and to ascertain the date of diagnosis, the presence and nature of any symptoms, the procedure performed to confirm the diagnosis (for example, barium study or endoscopy), treatment, and whether there were any dietary changes

TABLE I Relative risk (RR) of symptomatic diverticular disease in relation to categories of total energy, body mass index, and height

\begin{tabular}{|c|c|c|c|c|c|c|}
\hline \multirow[b]{2}{*}{ Variable } & \multicolumn{5}{|l|}{ Category } & \multirow{2}{*}{$\begin{array}{l}p \text { Value } \\
\text { for } \\
\text { trendt }\end{array}$} \\
\hline & 1 & 2 & 3 & 4 & 5 & \\
\hline Total energy (median kcal/d): & 1230 & 1586 & 1884 & 2226 & 2802 & \\
\hline Cases & 73 & 77 & 70 & 92 & 70 & \\
\hline $\mathbf{R R}^{\star}$ & 1.0 & 1.07 & 0.97 & $1 \cdot 32$ & $1 \cdot 04$ & 0.47 \\
\hline$(95 \% \mathrm{CI})$ & - & $(0.78,1.48)$ & $(0.70,1.35)$ & $(0.97,1.80)$ & $(0 \cdot 75,1 \cdot 44)$ & \\
\hline Multivariate $R \mathbf{R} \ddagger$ & $1 \cdot 0$ & $1 \cdot 10$ & 0.99 & 1.35 & $1 \cdot 04$ & 0.51 \\
\hline$(95 \%$ CI & - & $(0 \cdot 80,1 \cdot 52)$ & $(0 \cdot 71,1.38)$ & $(0.99,1 \cdot 84)$ & $(0 \cdot 75,1 \cdot 45)$ & \\
\hline BMIS (median $\mathrm{kg} / \mathrm{m}^{2}$ ): & 22 & $23 \cdot 7$ & $25 \cdot 1$ & $26 \cdot 5$ & $29 \cdot 4$ & \\
\hline Cases & 60 & 70 & 79 & 81 & 83 & \\
\hline $\mathbf{R R}^{\star}$ & $1 \cdot 0$ & $1 \cdot 16$ & $1 \cdot 28$ & 1.33 & 1.39 & 0.05 \\
\hline$(95 \% \mathrm{CI})$ & - & $(0.82,1.63)$ & $(0.91,1.80)$ & $(0.95,1 \cdot 87)$ & $(0.99,1.96)$ & \\
\hline Multivariate RR & $1 \cdot 0$ & 1.15 & 1.23 & 1.23 & 1.22 & $0 \cdot 38$ \\
\hline $\begin{array}{l}(95 \% \mathrm{CI}) \\
\text { Height } \$(\text { median } \mathrm{cm})\end{array}$ & $17 \overline{0}$ & ${ }_{175}^{(0.81,1 \cdot 62)}$ & $\begin{array}{l}(0 \cdot 87,1 \cdot 72) \\
178\end{array}$ & $\begin{array}{l}(0 \cdot 88,1 \cdot 72) \\
183\end{array}$ & $\begin{array}{l}(0 \cdot 87,1 \cdot 70) \\
188\end{array}$ & \\
\hline Cases & 114 & 46 & 123 & $\begin{array}{r}103 \\
47\end{array}$ & $\begin{array}{r}100 \\
52\end{array}$ & \\
\hline $\mathbf{R}^{\star} \mathbf{R}^{\star}$ & $1 \cdot 0$ & 0.93 & $\begin{array}{r}0.99 \\
(0.77,1.28)\end{array}$ & $\begin{array}{r}0.89 \\
(0.63 \\
1.25)\end{array}$ & $\begin{array}{ll}0.86 \\
0.62\end{array}$ & $0 \cdot 31$ \\
\hline $\begin{array}{l}(95 \% \text { CI) } \\
\text { Multivariate RR } \neq\end{array}$ & $1 \cdot 0$ & $\begin{array}{l}(0.66,1.31) \\
0.94\end{array}$ & 0.99 & $\begin{array}{l}(0 \cdot 63,1 \cdot 25) \\
0.89\end{array}$ & $\begin{array}{l}(0 \cdot 62,1 \cdot 19) \\
0 \cdot 83\end{array}$ & $0 \cdot 26$ \\
\hline$(95 \% \mathrm{CI})$ & - & $(0 \cdot 66,1 \cdot 32)$ & $(0 \cdot 77,1 \cdot 28)$ & $(0.63,1.26)$ & $(0.59,1 \cdot 15)$ & \\
\hline
\end{tabular}

^Adjusted for age. $\dagger$ Test for trend was calculated by using the median value of the variables in each quintile as continuous in a multiple logistic regression. ¥Adjusted for age, physical activity, energy adjusted dietary fibre, and energy adjusted total fat. multiple logistic regression. $¥$ Adjusted for age, physical activity, energy adjusted
§Numbers of cases do not always add to 382 because of missing information. 
TABLE II Relative risk (RR) of symptomatic diverticular disease in relation to physical activity, non-vigorous and vigorous activity levels, television and video watching

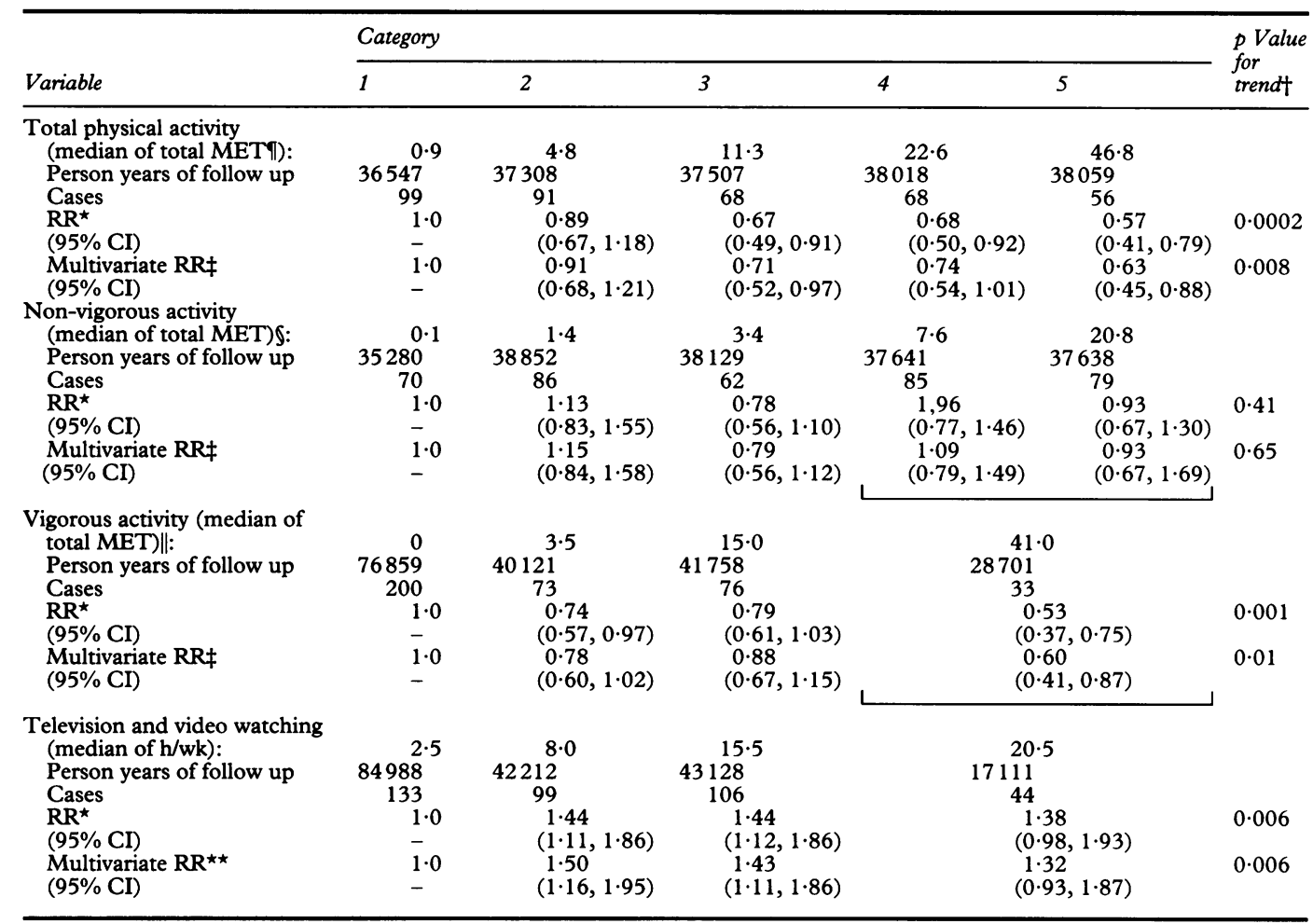

^Adjusted for age. $†$ Test for trend was calculated by using the median total MET value of exercise in each category as a continuous variable in a multiple logistic regression. $\ddagger$ Adjusted for age, energy adjusted dietary fibre and energy-adjusted total fat. continuous variable in a multiple logistic regression. ¥Adjusted for age, energy adjusted dietary fibre and energy-adjusted total fat.
§ncluded flight of stairs climbed and walking or hiking outdoors (including walking at golf). |Included running (10 $\mathrm{min} / \mathrm{mile}$ or Included flight of stairs climbed and walking or hiking outdoors (including walking at golf). IIncluded running (10 $\mathrm{min} / \mathrm{m}$.
faster), jogging (slower than $10 \mathrm{~min} / \mathrm{mile}$ ), lap swimming, tennis, squash or racquetball, calisthenics or rowing, bicycling (including stationary machines). ITotal MET =sum of the average time/wk spent in each activity $\times$ MET value of each activity. MET value $=$ caloric need $/ \mathrm{kg}$ body wt/h during activity caloric need/kg body wt/h at rest.

$\star \star$ Adjusted for age, physical activity, energy adjusted dietary fibre, and energy adjusted total fat.

induced by symptoms which occurred before the diagnosis. We obtained 182 medical records from a sample of participants who reported diverticular disease to assess the validity of self reporting, and to ascertain the site of the diverticula. The records confirmed the self reporting in $95 \%$ of the cases. We therefore accepted the other self reports of diverticular disease as valid. In addition, $96 \%$ of the cases were located in the left colon (sigmoid, descending, or mid-transverse colon), as would be expected in a predominantly white population. ${ }^{29} \mathrm{We}$ included in the analysis the cases diagnosed during the four years of follow up -1 February 1988 to 31 January 1992.

In the population eligible for analysis, we identified 500 newly diagnosed cases of diverticular disease. Of these, 382 were classified as symptomatic (presenting with pain, change in bowel habits, or bleeding), ${ }^{30}$ and 118 cases were classified as asymptomatic (the diverticula were discovered during a routine screening). To reduce the possibility of detection bias, we used symptomatic diverticular disease as our primary end point.

\section{STATISTICAL ANALYSIS}

Participants were categorised according to quintiles of total physical activity, nonvigorous activity, BMI, height, and total energy intake, and by four categories of vigorous activity (58\% of participants were engaged in vigorous activities). For each participant, the follow up time was calculated as the number of months between 1 February 1988 and the date of diagnosing diverticular disease or death, or 31 January 1992, whichever came first. The relative risk - the incidence among the men in different exposure categories divided by the corresponding rate in the reference category - was used as the measure of association. ${ }^{31}$ Age adjusted rates were calculated with the use of five year categories. The Mantel extension test ${ }^{32}$ was used to evaluate linear trends across categories of different variables. Other potentially confounding variables were modelled with multiple logistic regression. These variables included alcohol consumption, smoking, coffee intake, and other dietary variables (such as total fat and saturated fat). The variables were derived from the baseline questionnaire completed by the participants in 1986 . The $\mathrm{p}$ values are all two tailed, and for all relative risks we calculated the $95 \%$ confidence interval. ${ }^{33}$

\section{Results}

During 187439 person years of follow up over a period of four years, 382 cases of symptomatic diverticular disease were documented in this cohort. The predominant symptoms were abdominal pain $(63 \%)$, bleeding $(18 \%)$, and change in bowel habits (8\%). Age adjusted total energy intake and height were not signifi- 
TABLE III Relative risk (RR) of symptomatic diverticular disease in relation to specific exercises

\begin{tabular}{|c|c|c|c|c|c|}
\hline \multirow[b]{2}{*}{ Variable } & \multicolumn{4}{|l|}{ Frequency } & \multirow{2}{*}{$\begin{array}{l}p \text { Value } \\
\text { for } \\
\text { trendt }\end{array}$} \\
\hline & 1 & 2 & 3 & 5 & \\
\hline $\begin{array}{l}\text { Walking (median of total } \\
\text { MET): } \\
\text { Person years of follow up } \\
\text { Cases } \\
\text { Multivariate RR } \text { RR }^{\star} \\
(95 \% \text { CI })\end{array}$ & $\begin{array}{c}0 \\
43430 \\
90 \\
1 \cdot 0 \\
-\end{array}$ & $\begin{array}{l}0 \cdot 8 \\
31682 \\
62 \\
0 \cdot 89 \\
(0 \cdot 65,1 \cdot 24)\end{array}$ & $\begin{array}{l}3 \cdot 0 \\
35016 \\
63 \\
0 \cdot 84 \\
(0 \cdot 60,1 \cdot 15)\end{array}$ & $\begin{array}{l}7 \cdot 5 \\
41610 \\
91 \\
0.97 \\
(0 \cdot 72,1 \cdot 30) \\
\end{array}$ & 0.67 \\
\hline $\begin{array}{l}\text { Stair climbing (median of } \\
\text { total MET): } \\
\text { Person years of follow up } \\
\text { Cases } \\
\text { Multivariate } \mathrm{RR}^{\star} \\
(95 \% \mathrm{CI})\end{array}$ & $\begin{array}{c}<0 \cdot 1 \\
83220 \\
178 \\
1 \cdot 0 \\
-\end{array}$ & $\begin{array}{c}0 \cdot 4 \\
38628 \\
80 \\
1 \cdot 00 \\
(0 \cdot 77,1 \cdot 30)\end{array}$ & $\begin{array}{l}0 \cdot 8 \\
39122 \\
73 \\
0.93 \\
(0 \cdot 71,1 \cdot 22)\end{array}$ & $\begin{array}{l}1 \cdot 3 \\
26469 \\
51 \\
0.93 \\
(0 \cdot 68,1 \cdot 28) \\
\end{array}$ & 0.52 \\
\hline $\begin{array}{l}\text { Cycling (median of total } \\
\text { MET): } \\
\text { Person years of follow up } \\
\text { Cases } \\
\text { Multivariate } \mathrm{RR}^{\star} \\
(95 \% \mathrm{CI})\end{array}$ & $\begin{array}{c}0 \\
139474 \\
306 \\
1 \cdot 0 \\
-\end{array}$ & $\begin{array}{l}1 \cdot 4 \\
24516 \\
41 \\
0 \cdot 85 \\
(0 \cdot 61,1 \cdot 18)\end{array}$ & $\begin{array}{l}7 \cdot 0 \\
9493 \\
14 \\
0 \cdot 75 \\
(0 \cdot 44,1 \cdot 29)\end{array}$ & $\begin{array}{c}17 \cdot 5 \\
13956 \\
21 \\
0 \cdot 78 \\
(0 \cdot 50,1 \cdot 22) \\
\end{array}$ & $0 \cdot 21$ \\
\hline $\begin{array}{l}\text { Rowing and calesthenics } \\
\text { (median of total MET): } \\
\text { Person years of follow up } \\
\text { Cases } \\
\text { Multivariate RR` } \\
(95 \% \mathrm{CI})\end{array}$ & $\begin{array}{c}0 \\
143529 \\
304 \\
1 \cdot 0 \\
-\end{array}$ & $\begin{array}{c}3 \cdot 0 \\
22508 \\
42 \\
0 \cdot 97 \\
(0 \cdot 70,1 \cdot 34)\end{array}$ & $\begin{array}{l}6.0 \\
9341 \\
17 \\
0.95 \\
(0.58,1.55)\end{array}$ & $\begin{array}{c}15 \cdot 0 \\
12061 \\
19 \\
0 \cdot 87 \\
(0 \cdot 55,1 \cdot 39)\end{array}$ & 0.53 \\
\hline $\begin{array}{l}\text { Jogging and running } \\
\text { (median of total MET): } \\
\text { Person years of follow-up } \\
\text { Cases } \\
\text { Multivariate } \mathrm{RR}^{\star} \\
(95 \% \mathrm{CI})\end{array}$ & $\begin{array}{c}0 \\
144990 \\
331 \\
1 \cdot 0 \\
-\end{array}$ & $\begin{array}{c}3.5 \\
16566 \\
23 \\
0.79 \\
(0.51,1 \cdot 20)\end{array}$ & $\begin{array}{c}12 \cdot 0 \\
14088 \\
19 \\
0 \cdot 83 \\
(0.52,1 \cdot 33)\end{array}$ & $\begin{array}{c}27 \cdot 5 \\
11794 \\
9 \\
0 \cdot 52 \\
(0 \cdot 27,1 \cdot 0) \\
\end{array}$ & 0.03 \\
\hline $\begin{array}{l}\text { Swimming (median of total } \\
\text { MET): } \\
\text { Person years of follow up } \\
\text { Cases } \\
\text { Multivariate } \mathrm{RR}^{\star} \\
(95 \% \mathrm{CI})\end{array}$ & $\begin{array}{c}0 \\
170527 \\
344 \\
1 \cdot 0 \\
-\end{array}$ & $\begin{array}{l}14 \\
9477 \\
20 \\
1 \cdot 08 \\
(0 \cdot 69,1 \cdot 70)\end{array}$ & & $\begin{array}{l}10 \cdot 5 \\
7435 \\
18 \\
1 \cdot 26 \\
(0 \cdot 78,2 \cdot 02) \\
\end{array}$ & $0 \cdot 34$ \\
\hline $\begin{array}{l}\text { Racquet sports } \ddagger \text { (median of } \\
\text { total MET): } \\
\text { Person years of follow-up } \\
\text { Cases } \\
\text { Multivariate RR* } \\
(95 \% \text { CI) }\end{array}$ & $\begin{array}{c}0 \\
155397 \\
342 \\
1 \cdot 0 \\
-\end{array}$ & $\begin{array}{c}7 \cdot 0 \\
15253 \\
16 \\
0 \cdot 60 \\
(0 \cdot 36,0.99)\end{array}$ & & $\begin{array}{c}30 \cdot 0 \\
16789 \\
24 \\
0 \cdot 74 \\
(0 \cdot 49,1 \cdot 13)\end{array}$ & $0 \cdot 10$ \\
\hline
\end{tabular}

*Adjusted for age, energy adjusted dietary fibre and energy adjusted total fat. $\nmid$ Test for trend was calculated using the median total MET of spectific exercise in each category as a continuous variable in a multiple logistic regression.

$\ddagger$ Included tennis, squash, or racquetball.

cantly associated with the risk of diverticular disease ( $p$ for trend $=0.47$ for energy, 0.31 for height) (see Table I). We observed a positive association between the age adjusted BMI and the risk of symptomatic diverticular disease ( $p$ for trend $=0.05$ ) (see Table I). The associations between total energy intake, BMI, height, and risk of symptomatic diverticular disease were attenuated, when assessed separately in multivariate models with age, physical activity, energy adjusted dietary fibre, and energy adjusted total fat, and none was statistically significant (see Table I).

We examined the relationships of age adjusted total physical activity, vigorous activity, and non-vigorous activity with the risk of symptomatic diverticular disease. Total physical activity was inversely associated with the risk of symptomatic diverticular disease. Compared with men in the lowest quintile of physical activity, those in the highest quintile had a relative risk of $0.57(95 \%$ CI $0.41,0.79)$. Nearly all of this inverse association was attributable to the vigorous activities. The $R R$ comparing extreme categories of vigorous activity was $0.53(95 \%$ CI $0.37,0.75)$. In contrast, non-vigorous activity was not appreciably associated with risk of symptomatic diverticular disease $(R R=0.93,95 \%$ CI $0.67,1.30$ ) (see Table II). When we analysed separately total physical activity, vigorous activity, and non-vigorous activity in multivariate models with age, energy adjusted dietary fibre, and energy adjusted total fat, our findings did not change appreciably from those in the age adjusted model (see Table II). When we included vigorous activity and non-vigorous activity simultaneously in the multivariate model with age, energy adjusted dietary fibre, and energy adjusted total fat, our findings did not change appreciably ( $R R$ for vigorous activity $=0.60,95 \%$ CI $0.41,0.87$; $\mathrm{RR}$ for non-vigorous activity $=0.93,95 \% \mathrm{CI}$ $0.67,1.29)$. Vigorous activity accounted for $61 \%$ of the total physical activity score. Television viewing or video watching, an important indicator of inactivity, ${ }^{34}$ was positively associated with the risk of symptomatic diverticular disease ( $p$ for trend $=0.006$ ) (see Table II).

We also examined the various specific sports and recreational activities on the list in relation to the risk of symptomatic diverticular disease (see Table III). Several specific activities tended to be inversely associated with the risk of symptomatic diverticular disease, though most were not statistically significant. Age adjusted jogging and running combined, cycling, and racquet sports were the only sport activities that were statistically significant 


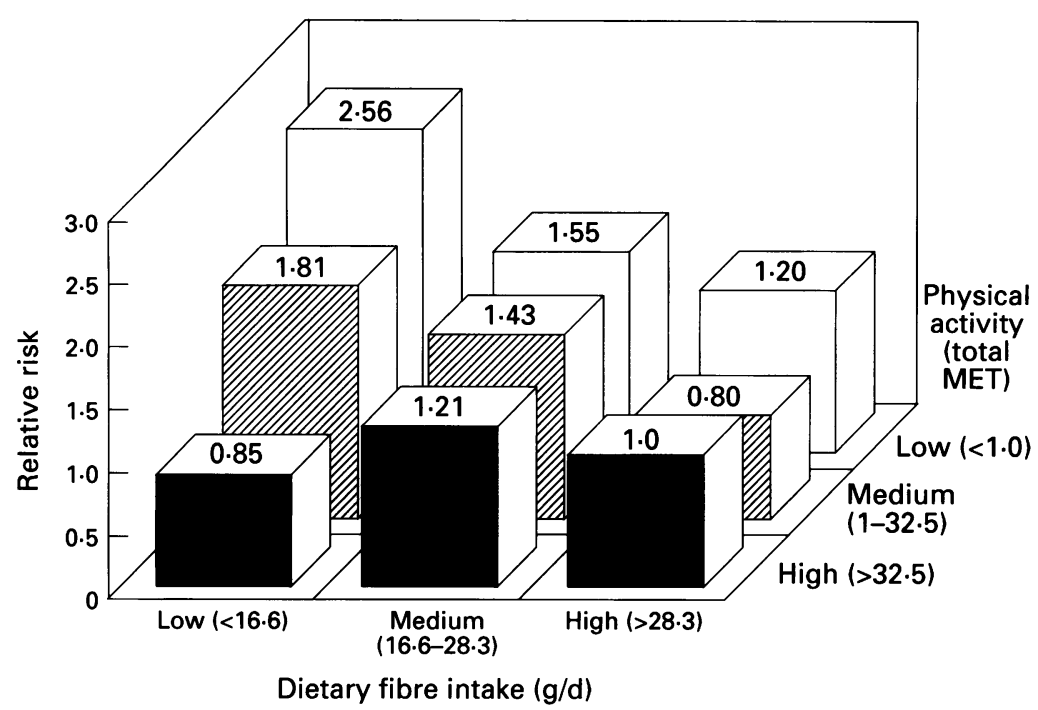

Relative risk (adjusted for age and total fat) of symptomatic diverticular disease in relation to levels of energy adjusted dietary fibre intake and physical activity.

( $p$ for trend $=0.007$ for jogging and running; $p$ for trend $=0.03$ for cycling; $p$ for trend $=0.03$ for racquet sports). When cycling, racquet sports, and jogging and running were analysed separately in a multivariate model including age, energy adjusted dietary fibre and energy adjusted total fat, cycling and racquet sports were no longer significant, while jogging and running retained statistical significance (see Table III). The associations between total and vigorous activity and risk of symptomatic diverticular disease were stronger among men under the age of 65 years (RR for total physical activity $=0.49,95 \%$ CI $0.33,0.74$; $R R$ for vigorous activity $=0.49,95 \%$ CI 0.32 , 0.77).

Using a multivariate model controlling for age and energy adjusted total fat, we examined the risk of symptomatic diverticular disease among the subjects classified jointly according to their intake of dietary fibre, and physical activity. For men in the lowest quintile for both dietary fibre and physical activity (compared with those in the opposite extreme), the relative risk of symptomatic diverticular disease was $2 \cdot 56,95 \%$ CI $1.36,4 \cdot 82$ (see Figure). The association between a low level of physical activity and the risk of symptomatic diverticular disease was strongest among men with low intake of fibre. However, the interactions between total or vigorous activity and dietary fibre were not statistically significant when examined in a multivariate model that also included age and energy adjusted total fat (for interaction, $\mathrm{p}=0.33$ with total physical activity; $\mathrm{p}=0.38$ with vigorous activity).

To evaluate the possibility that biased detection of diverticular disease might have occurred among individuals who had an endoscopic procedure for routine screening or for gastrointestinal conditions unrelated to diverticular disease, we restricted our analysis to the $\mathbf{3 4 8 4}$ participants who reported that they had colonoscopy or sigmoidoscopy, or both, between 1988 and 1992. Among these men, the relationships between physical activity and the risk of symptomatic diverticular disease, were similar to those in the analysis including all men. In this limited subset, we used the same multiple logistic regression model with age, energy adjusted dietary fibre, energy adjusted total fat, and compared the effect of high versus low levels of physical activity, using the same cut points as in the analysis. For total physical activity, the RR was 0.45 (95\% CI $0 \cdot 26,0 \cdot 78$ ).

\section{Discussion}

These prospective data suggest that physical activity, in general, and vigorous activity, in particular, reduce the risk of symptomatic diverticular disease. Risks were more notably raised among men with both low dietary fibre consumption and low physical activity. To our knowledge, a prospective assessment of physical activity has not been considered in previous studies of diverticular disease. Apart from reports of higher prevalence of diverticular disease in urban settings, or among sedentary occupations, ${ }^{35}$ the role of physical activity and its association with diverticular disease has not been explored in detail in previous studies.

In our data, there was a weak positive association between increasing BMI and the risk of symptomatic diverticular disease. In a recent study, more severe diverticular disease was reported to occur in young ( $<40$ years) obese men. ${ }^{36}$ We could not address this hypothesis, since the participants in our study are all over the age of 40 years.

We observed a reduced risk of symptomatic diverticular disease with increasing physical activity level particularly vigorous activity. Jogging and running were the only specific activities that were individually statistically significant after controlling for age, energy adjusted dietary fibre, and energy adjusted total fat. However, in these data, all the vigorous activities had a trend toward reduced risk, and it seems that the overall level of vigorous physical activity is the dominant factor and not any specific exercise.

A limited number of studies have addressed the effect of physical activity on colonic function, despite the widely held belief of a beneficial effect of exercise on gastrointestinal functions. A reduction in transit time was the consistent finding in most of the studies that addressed the effect of exercise on colonic function, ${ }^{18} 19$ although some did not observe such an effect. ${ }^{37}$ An increase in colonic motor activity has been postulated; however, the exact mechanism of this effect is still not clear. Some authors have suggested that the effect might be multifactorial, involving hormonal, vascular, and mechanical aspects. ${ }^{18}$ Whether physical activity influences diverticular disease through any of these or other mechanisms, and whether specific exercise (for example, jogging and running) has specific effects on colonic functions needs to be explored.

It has been argued that the abdominal pain associated with diverticular disease is a result of existing irritable bowel syndrome (IBS). Since both conditions are common, some overlap between them might exist. How- 
ever, the prevailing understanding is that diverticula can cause symptoms which vary from a mild left quadrant pain to severe abdominal pain, ${ }^{30}$ and in extreme cases perforation and bleeding. Moreover. IBS has a gradual onset as early as adolescence, ${ }^{38}$ compared with the much later and shorter presentation of symptomatic diverticular disease. In addition, patients with IBS have a much higher measure of anxiety and obsession, ${ }^{39}$ which is not a common finding in symptomatic diverticular disease. There are no concrete and uniform criteria which define IBS, and the only diagnostic criterion which is accepted is the absence of an organic lesion, ${ }^{40}$ making IBS a diagnosis of exclusion, which is not the case in symptomatic diverticular disease.

Since most cases of diverticular disease cases are asymptomatic, and diagnosis is made when affected individuals develop symptoms, we explored the possibility that the associations we observed were due to detection bias related to the participants' level of physical activity. We restricted the study population to subjects who had had endoscopies within our follow up period to eliminate the possibility of any spurious associations due to any relationship between physical activity and the rate of endoscopy. Among the subpopulation of men with recent endoscopies, our findings were not appreciably different from those in the eligible cohort; indeed, the association was even slightly stronger, though this difference was not statistically significant. We also examined the possibility that the rate of endoscopies for abdominal symptoms among our participants (excluding symptomatic diverticular disease cases), might be related to their level of physical activity (for example, people who are not physically active might have more abdominal symptoms, and hence more endoscopies). However, the opposite was found, in that those participants who reported having endoscopies for abdominal symptoms (unrelated to diverticular disease) were in fact exercising more and eating more fibre. We therefore conclude that detection bias is unlikely to have appreciably influenced our results.

Because we relied mainly on self report rather than obtaining complete medical records for all the positive respondents, we could not exclude right sided diverticulosis from our cases. However, among the 108 cases from whom we obtained medical records, exclusively right sided diverticulosis was present in less than $4 \%$, which is what is expected in a western population. ${ }^{29}$ This is in contrast to the orient where diverticular disease is predominantly right sided. ${ }^{41-43}$

Biased recall of physical activity was unlikely, because the physical activity data were collected before the diagnosis of symptomatic diverticular disease. We have controlled for potential risk factors such as age, dietary fibre, total fat, types and sources of fat, smoking, alcohol, and socioeconomic status by the nature of our population of male health professionals. We recognise that some degree of misclassification in physical activity is inevitable. However, the prospective design of this study means that any misclassification would be random with regard to case status, and hence would tend to attenuate any association. Our findings are most directly generalisable to US men 40 years and older. Apart from reports of higher preponderance of diverticular disease in women, ${ }^{2}$ we have no reason to believe that the relations we observed in men would be different.

Our findings suggest that increasing levels of physical activity reduce the risk of symptomatic diverticular disease. They also provide evidence that the combination of low physical activity and a diet low in fibre particularly augments the risk.

We are indebted to the participants in the Health Professionals Follow-up Study for making this study possible; to Drs John Kearney, Gary Curhan, and to Ms Mary Johnson, Mrs Betsy Frost-Hawes, Ms Mitzy Wolff, Ms Cindy Dyer, Ms Jan Frost-Hawes, Ms Mitzy Wolff, Ms Cindy Dyer, Ms Jan
Vomacka, Ms Kerry Pillsworth, Mrs Mira Koyfman, and Mrs Vomacka, Ms Kerry Pillsworth, M

Supported in part by research grants (HL35464 and CA55075) from the National Institute of Health

1 Walkers DAK, Smith AN. Strength of the colon wall in diverticular disease. Br f Surg 1990; 77: 257-9.

2 Roberts PL, Veidenheimer MC. Diverticular disease of the colon. In: Bayless TM, ed. Current therapy in gastroenterology and liver diseases - 3. Toronto, Philadelphia: BC Decker Inc, 1990: 416-9.

3 Schwartz JT, Graham DY. Diverticular disease of the large intestine. In: Kirsner J, Shorter R, eds. Diseases of the colon, rectum, and anal canal. Baltimore: Williams and Wilkins, 1988: $519-36$.

4 Thompson WG, Patel DG. Clinical picture of diverticular disease of the colon. Clin Gastroenterol 1986; 15: 903-16. 5 Painter NS, Burkitt DP. Diverticular disease of the colon: A 20th century problem. Clin Gastroenterol 1975; 4: 3-21.

6 Painter NS, Burkitt DP. Diverticular disease of the colon: a deficiency disease of western civilization. BMF 1971; 2: 450-4

7 Painter N. Diverticular disease of the colon. In: Trowell $\mathrm{H}$, Burkitt D, Heaton K, eds. Dietary fibre, fibre-depleted foods and diseases. London: Academic Press Inc, 1985: 145-60.

8 Brodribb AJM, Humphrey DM. Diverticular disease; three studies. I. Relation to other disorders and fibre intake. studies. I. Relation to

9 Leaky AL, Ellis RM, Quill DS, Peel ALG. High fibre diet in symptomatic diverticular disease of the colon. Ann $R$ Coll Symptomatic diverticular disea

10 Manousos O, Day NE, Tzonou A, Papadimitriou C, Kapetanakis A, Polychronopoulou-Trichopolou A, et al. Diet and other factors in the aetiology of diverticulosis: an epidemiological study in Greece. Gut 1985; 26: 544-9.

11 Miettinen TA, Tarpila S. Fecal beta-sitosterol in patients with diverticular disease of the colon and in vegetarians. Scand f Gastroenterol 1978; 13: 573-6.

12 Gear JSS, Ware A, Fursdon P, Mann JI, Nolan DJ, Brodribb AJM, et al. Symptomless diverticular disease and intake of dietary fiber. Lancet 1979; i: 511-4.

13 Findlay JM, Smith AN, Mitchell WD, Anderson AJB, Eastwood MA. Effects of unprocessed bran on colon function in normal subjects and in diverticular disease. Lancet 1974 ; i: 146-9.

14 Hodgson WJB. An interim report on the production of colonic diverticula in the rabbit. Gut 1972; 13: 802-4

15 Fisher N, Berry CS, Fearn T, Gregory JA, Hardy J. Cereal dietary fiber consumption and diverticular disease: a lifespan study in rats. Am $\mathcal{f}$ Clin Nutr 1985; 42: 788-804.

16 Jaskiewicz K, Rossouw JE, Kritchevsky D, Van Resburg SJ, Fincham JE, Woodroff $\mathrm{CW}$. The influence of diet and diemethyhydrazine on the small and large intestine of Vervet monkeys. British fournal of Experimental Pathology 1986; 67: 361-9.

17 Dapoigny M, Sarna SK. Effects of physical exercise on colonic motor activity. Am $\mathcal{f}$ Physiol 1990; 260: G646-52.

18 Oettle GJ. Effect of moderate exercise on bowel habit. Gut 1991; 32: 941-4.

19 Koffler KH, Menkes A, Redmond RA, Whitehead WE, Pratley RE, Hurley BF. Strength training accelerates gastrointestinal transit in middle-aged and older men Med Sci Sports Exerc 1992; 24: 415-9.

20 Sullivan SN. The effect of running on gastrointestinal tract. $\mathcal{F}$ Clin Gastroenterol 1984; 6: 461-5.

21 Siconolfi SF, Lasater TM, Snow RCK, Carleton RA. Self reported physical activity compared with maximal oxygen uptake. Am ₹ Epidemiol 1985; 122: 101-5.

22 Albanes D, Conway JM, Taylor PR, Moe PW, Judd J. Validation and comparison of eight physical activity questionnaires. Epidemiology 1990; 1: 65-71.

23 Hopkins WG, Wilson NC, Russell DG. Validation of the physical activity instrument for the life in New Zealand national survey $\mathcal{f}$ Epidemiol 1991; 133: 37-82. 
24 Wolf A, Colditz GA, Hunter D, Stampfer MJ, Manson JE, Troy L, et al. Validity of a self-administered physical activity questionnaire in the nurses' health study [Abstract]. Am $\mathcal{F}$ Epidemiol 1992; 136 (8): 992.

25 Ainsworth BE, Haskell WL, Leon AS, Jacobs DR, Montoy $\mathrm{HJ}$, Sallis JF, et al. Compendium of physical activities: HJ, Sallis JF, et al. Compendium of physical activities: Med Sci Sports Exerc 1993; 25: 71-80.

26 Rimm EB, Giovannucci EL, Stampfer MJ, Colditz GA, Litin LB, Willett WC. Reproducibility and validity of an expanded self-administered semiquantitative food frequency questionnaire among male health professionals. Am f Epidemiol 1992; 135: 1114-26.

27 Paul AA, Southgate DA. McCance and Widdowson's the composition of foods. 4th ed, rev. London: Her Majesty's Stationery Office, 1978.

28 Southgate DA, Bailey B, Collinson E, Walker AF. A guide to calculating intakes of dietary fiber. $\mathcal{F}$ Hum Nutr 1976; to calculating intakes of dietary fiber. F Hum Nutr 1976; 30: 303-13.

29 Parks TG. Natural history of diverticular disease of the colon; a review of 521 cases. BMF 1969; 4: 639-45.

30 Painter NS. The cause of diverticular disease of the colon; Its symptoms and its complications. $\mathcal{f} R$ Coll Surg Edin 1985; 30: 118-22.

31 Rothman KJ. Modern epidemiology. Boston: Little, Brown and Company, 1986

32 Kleinbaum DG, Kupper LL, Muller KE. Applied regression analysis and other multivariable methods. Boston: PWSKENT Publishing, 1988.

33 Miettinen $O$. Estimability and estimation in case-referent studies. Am $\mathcal{F}$ Epidemiol 1976; 103: 226-35.
34 Gortmaker DG, Dietz WH, Cheung LWY. Inactivity, diet, and the fattening of America. 7 Am Diet Assoc 1990; 90: $1247-52,1255$.

35 Manousos ON, Vrachliotis G, Papaevangelou G, Detorakis $\mathrm{E}$, Doritis P, Stergiou L, et al. Relation of diverticulosis of E, Doritis P, Stergiou L, et al. Relation of diverticulosis of the colon to enviro

36 Dchauer PR, Ramos R, Ghiatas AA, Sirinek KR. Virulent diverticular disease in young obese men. Am $\mathcal{F}$ Surg 1992; 164: 443-8.

37 Bingham SA, Cummings JH. Effect of exercise and physical fitness on large intestinal function. Gastroenterology 1989; 97: 1389-99.

38 Weber FH, McCallum RW. Clinical approaches to irritable bowel syndrome. Lancet 1992; 340: 1447-52.

39 Kumar D, Pfeffer J, Wingate DL. Role of psychological factors in the irritable bowel syndrome. Digestion 1990; 45: 80-7.

40 Christensen J. Pathophysiology of the irritable bowel syndrome. Lancet 1992; 340: 1444-7.

41 Lee YS. Diverticular disease of the large Bowel in Singapore: an autopsy study. Dis Colon Rectum 1986; 29: 330-5.

42 Chia JG, Chiantana CW, Ngoi SS, Goh PM. Ong CL. Trends of diverticular disease of the large bowel in a newly developed country. Dis Colon Rectum 1991; 34: 498-501.

43 Vajrabukka T, Saksornchai K, Jimakorn P. Diverticular disease of the colon in a far-eastern community. Dis Colon Rectum 1980; 23: 151-4. 